\title{
Measuring Microbiome Effectiveness: A Role for Ingestible Sensors
}

\author{
David Smith * and Sohan Jheeta * \\ NoR CEL, (formerly NoR HGT \& LUCA), Leeds LS7 3RB, UK \\ * Correspondence: dave.smithathome@gmail.com (D.S.); sohan@sohanjheeta.com (S.J.)
}

Received: 12 September 2019; Accepted: 23 January 2020; Published: 28 January 2020

\begin{abstract}
Across the world there is an increasingly heavy burden of noncommunicable diseases related to obesity, mental health, and atopic disease. In a previous publication, we followed the developing idea that that these conditions arise as our microbiome loses diversity, but there seems to be no generally applicable way to assess the significance of this loss. Our work revisited the findings of the African studies by Denis Burkitt who reported that the frequency of what he called Western diseases were inversely proportional to the average faecal volumes of affected populations. Although he ascribed this to fibre in the diet, it now seems more likely that the drop in faecal volume with the onset of disease is due to the loss of a fully functioning microbiome. We suggested that the microbiome could be considered to be a single mutualistic microbial community interacting with our body by two complementary sets of semiochemicals, i.e., allomones to feed the microbiota by facilitating the efficient transfer of nutrition through the gut and kairomones to calibrate our immune system by an as yet unknown mechanism. The bioactive compounds, dopamine and serotonin, are known to be present in the gut lumen under the influence of intestinal microbiota and we suggest that these are part of this allomone-like system. In light of this possibility, it is of critical importance to develop a method of quantifying the microbiome effectiveness. Ingestible sensors consist of a miniaturized detector and transmitter packed into a capsule that is swallowed and tracked through the intestine. The aim of this article is to explore the possible development of such ingestible detectors for these or other compounds that can act as a surrogate marker for microbiome effectiveness. We consider that the ability to provide real-time quantitative information on the interaction of the microbiome with different nutrients promises to be a valuable new tool to unravel the mystery of these noncommunicable illnesses, i.e., microbiome-function deficiency diseases.
\end{abstract}

Keywords: atopic disease; dopamine; dysbiosis; ingestible sensors; mental health; microbiome; noncommunicable disease; obesity; semiochemical; sentinel cells; serotonin; Tsimane

\section{Introduction: The Microbiome in Health and Disease}

There is an increasing incidence of noncommunicable diseases such as obesity [1], mental health problems [2], and atopic disease [3] which are all diseases that are associated with immune system defects stemming from a disturbance of the microbiome [4-6]. Similar to autoimmune diseases that either affect the intestine itself [7] or sites remote from the intestine [8], type 1 diabetes [9] and cancer have also been associated with immune system defects stemming from disturbance of the microbiome [10]. It seems that an effective microbiome is critical during early life, especially in the calibration of the developing immune system [11]. The purpose of this article is to briefly consider the possibility of detecting suitable microbial metabolites with the goal of assessing the effectiveness of the human intestinal microbiome.

As with the previous paper [12], the term microbiota is used to indicate actual microbial species, whereas microbiome refers to the sum total of microbes expressing genes that are mainly beneficial to 
the host; this is because humans evolved within the world of microbes and viruses. Therefore, the microbiome is considered to be more important than individual microbes because useful genes or their phenotypic products can be shared between widely different species [13]. The word dysbiosis [14] is used to describe the partial failure of the microbiome.

\section{Horizontal Gene Transfer}

The overall interaction and control between the constituent organisms in microbiomes relies on the process of horizontal gene transfer (HGT). To wholly understand how living organisms, especially microbial ones, obtain physiological properties and metabolic characteristics which they did not previously have, means having to invoke and understand mechanisms of mobile genetic elements (MGEs), i.e., the exchange or transfer of only a few genes. This process is generally referred to as HGT, as opposed to the process of vertical gene transfer which occurs during sexual reproduction when the entire genome is transferred to the progeny. There are three such mechanisms, namely bacterial transformation [15], bacterial conjugation [16], and transduction [17,18]. All three HGTs are operational in the human gut, probably simultaneously, transferring genes across species, genera, and even phyla. In short, bacterial transformation occurs when MGEs from lysed microbial cell contents are taken up by other living cells; bacterial conjugation takes place between two living microbial cells, i.e., between the host and competent recipient cells via sex tubes, namely pili. In this respect, the process is an active one and is imitated by the host cell, meanwhile the recipient cells remain passive during conjugation. Finally, transduction happens when phage-infected microbial cells, upon their demise (lysis), release phages that are packed with host cell MGEs and infect other microbial cells, thereby transferring the traits of the host cells to the recipient cells. In all three cases, the recipient cell is transformed due to integration and subsequent recombination of the incoming MGEs with its chromosome. In the context of the human microbiome, HGT, the shedding of genes and the theft of metabolic products is becoming an important factor in health and disease. Koumandou and co-workers mapped the distribution of nine bioenergetic modes using 16S rRNA (more later) sequences from 272 species of fully sequenced prokaryotes, which represented the full diversity of prokaryotic ancestries. They reported that there was an irregular distribution of metabolic pathways among different lineages due to gene transfer events and an ancient origin and diversification of b-type cytochromes, which means that bioenergetic pathways were dynamic amid the human gut microbial community [19-21].

\section{Microbiome Diversity: Probiotics and Sentinel Cells}

Previous research has focused mostly on individual microbial species and their variation in different disease states. However, it is now clear that individual species vary widely in response to many different conditions, even in the absence of overt disease. Microbiome function, in which valuable genes are expressed by several different species, is likely to be more important than actual microbial entities [22]. In this way, the diversity of the microbiome insures it against the suppression of individual microbes, for example, if there is a significant change in the diet [23]. An individual with low diversity of gut microbiota is vulnerable to diseases if events (or lifestyle choices) mean that there is insufficient residual microbial activity to supply the necessary semiochemicals. Effectively, these noncommunicable diseases are considered to be deficiency diseases, and therefore, in principle, they can be treated by the addition of probiotics to the diet [24].

Commercial probiotics can reduce the risk of antibiotic-induced diarrhea and necrotising enterocolitis in premature babies [25], especially alongside prebiotic treatment [26]. An effective treatment for Clostridium difficile overgrowth is provided by the ultimate probiotic, faecal microbiota transplantation (FMT), in which the whole microbiome is replaced in one go [27,28]. If the microbiome is not too severely affected, for example, in the attempted treatment of ulcerative colitis, FMT requires several treatments or is not effective at all [29].

It has been found that the presence of yogurt-derived microbes in the diet of mice was enough to evoke an immune response without changing the apparent nature of their microbiome [30]. 
This dietary microbe immune-stimulating effect was absent in germ-free mice, suggesting that the intestinal microbiome acts as an intermediary between external microbes and the immune system [30]. It seems that the interrogation of external microbes by the in situ microbiome can pass information back to indirectly activate the host immune system, rather than direct action between external microbes and the host immune system itself. In an earlier paper, we termed such interrogating species "microbial sentinel cells" [12] and suggested that they are the same as the "old friends" of Rook and co-workers [6]. The implication is that added probiotics could have the same effect as lightly processed foods in which environmental microbes are retained. It is important to note that external microbes damaged by heating could still elicit a positive response if sufficient antigens are present to activate these sentinel cells, reminiscent of Griffith's transforming factor experiments [15]. In the same manner, enough plasmid particles can survive excessive heat during cooking to be recognized and included within the genome of appropriate microbiota.

The HGT's processes explain the mechanisms by which exogenous genes become incorporated. For example, consider transformation during the lysis of bacteriophages, MGEs which contain resistance gene elements are released and, then, taken up by surrounding microbes, and therefore confer antibiotic resistance [31]. Such widespread HGT [32,33] is expected to result in the spread of genes between different genera and even phyla of microbes within the diverse microbiome [34]. Bacteria and archaea [35] contribute the greater amount during gene transfer; whereas microeukaryotes including amoebae and even some fungal species [36] also play a part, but much less is known about the role of these groups of organisms.

Because microbial communities are composed of hundreds of different species containing members of all three microbial domains of life, namely archaea, bacteria, and eukarya, we consider it unlikely that we would be able to gain much understanding from the resultant multitude of individual interactions. Accordingly, the microbiome is best considered as a whole; it is this collective interaction between various organisms that is important, including the host, in this respect humans [12]. Interestingly, Margulis first raised the concept of an intact microbiome acting in concert with the host as a single evolutionary unit as far back as 1991 [37]. The term used was "holobiont" [38]. Although it is still under active discussion, the holobiont concept could be applied to both our body and our mutualistic microbiome. This term could also be applied to other animals and could be common to all vertebrate species to a greater or lesser extent.

\section{Detecting Diversity and Overall Composition of the Microbiome}

In general, the challenge with the microbiome is that we are only able to grow less than $5 \%$ of the microbial species in a laboratory, the rest are simply too fastidious. However, studies involving techniques such as polymerase chain reactions (PCR) do at least tentatively identify the ribosomal RNA (rRNA) of the known micro-organisms; rRNAs, in particular 16S rRNA or 18S rRNA, that are found in all cellular life forms, are ideal for such investigations as they are highly conserved. 16S rRNA is the preserver of all prokaryotes [39] and 18S rRNA is part and parcel of all eukaryotes [40], whereas " $\mathrm{S}$ " in $16 \mathrm{~S} / 18 \mathrm{~S}$ is a Svedberg unit of sedimentation, noting that the ribosomes of the former are smaller and lighter (70S and $2700 \mathrm{kDa})$ in weight than the latter ( $80 \mathrm{~S}$ and $4200 \mathrm{kDa})$. This technique is a process whereby ribosomal genes (strictly speaking ribosomal transcripts), i.e., the DNA segments which code for 16S/18S rRNAs, are highly conserved, and therefore unique to each separate species. In order to make rRNA identification possible, the following three aspects of the conserved regions are necessary: Initially, the conserved genes to be studied need to be universally distributed in all cellular species. Secondly, to identify highly conserved homologous segments of such genes, the conserved regions must, first, be isolated and, then, placed side by side for comparing and contrasting differences in sequences within them. These differences give new genotypic attributes to the newly emerging species. Finally, the rate of point mutations within the conserved region needs to be at acceptable levels and must be due to natural causes, normally taking millions of years rather than a rapid change as experienced by the genome in general. After confirmation of these three requirements, amplification of 
the conserved segments can be brought about by using polymerase enzymes so as to make it possible to detect microbes within microbiomes.

\section{The Mutualistic Microbiome: Dysbiosis}

Our previous publication [12] followed up the observations of Burkitt during his travels in Africa after the Second World War. Burkitt noted that rural Africans ate large amounts of fibre and passed stools three to five times more massive than that of typical inhabitants of developed countries. He also noted the absence of what he termed "characteristic modern Western diseases" in his subjects [41]. We developed this observation in light of the current understanding of the microbiome and suggested that various substances released by the microbiota behave as semiochemicals [42], representing the mutualistic interaction of human organs with various microbial metabolites (not exclusively the intestine $[7,8]$ ). In particular, we considered that substances such as dopamine and serotonin act to improve gut motility, i.e., the coordination of nerves and muscles allow the smooth transit of the gut contents [43-45]. In this way, the microbiome receives adequate nutrition to perform its role which is to calibrate the immune system [12]. This mechanism would explain the high faecal volumes noted by Burkitt [41]. By contrast, the failure of these semiochemical systems leads to a fall in faecal volume and a corresponding increase in the likelihood of disease (Figure 1). Note the use of an ingestible sensor to estimate the overall effectiveness of the microbiome (to be described later).

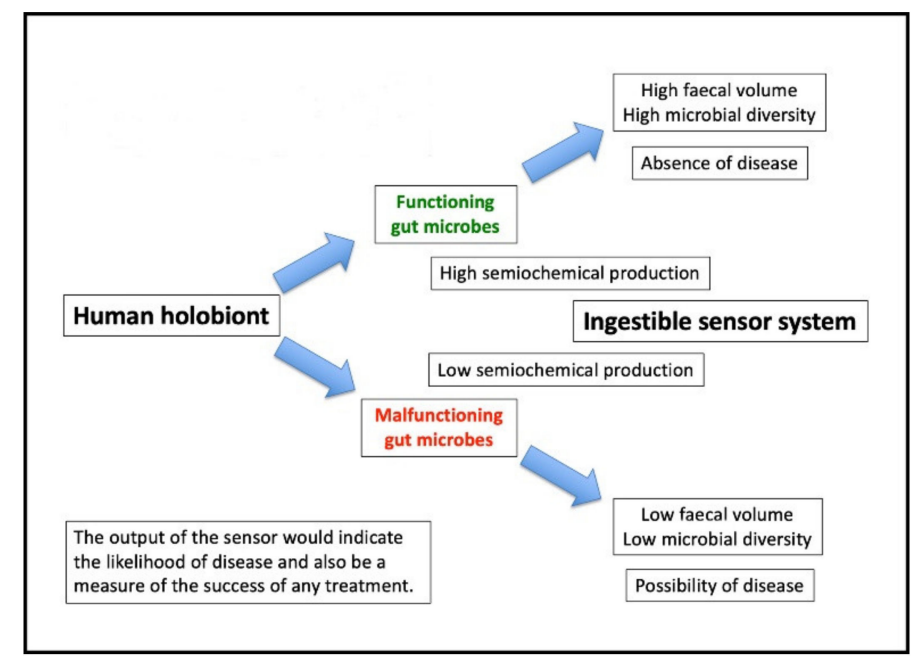

Figure 1. Illustrates the consequences of altered microbiome function and variable semiochemical production.

This concept of a single mutualistic microbiome, which has a semiochemical mode of action, albeit with variable interacting microbial species, offers valuable new insight into the development of microbiome-function deficiency diseases. It is important to realize that, to the best of our knowledge, there is no competing theory that brings the three modern plagues of obesity, altered immune function, and poor mental health under one single rationale. Equally, there are no quantitative data to support or refute our argument [12]. It is the purpose of this article to suggest a way to obtain such data.

\section{Ingestible Sensing Capsules in the Context of Microbiome Studies}

Ingestible sensors consist of a miniaturized detector and transmitter packed into a capsule that can be swallowed and tracked through the intestine. They have the capacity to revolutionize the study of the gut with a vast array of potential targets both for direct practical application and for research purposes. Some are commercially available, such as $\mathrm{pH}$, temperature, and pressure sensors, recently reviewed in [46]. A remote sensing procedure called colon capsule endoscopy has been developed to look at the inside of the gut wall using visible light and two video cameras transmitting pictures 
affording nearly 360 degree coverage to an external monitor. Its effectiveness has been reviewed relative to both conventional colonoscopy and computer tomography colonography [47]. For a slightly different purpose, a single-use remote sensing system has recently been developed to monitor compliance among people suffering from severe mental illness while taking a "digital pill" containing the atypical antipsychotic aripiprazole [48], an example of the expanding field of digital medicine [49]. Any sensing system capable of being miniaturized can be used. One recent example used bacteria that were themselves engineered to produce a luminescent signal on exposure to a specific agent. This signal was converted to a radio transmission for external monitoring. Their proof-of-concept studies used heme protein to detect bleeding in swine intestine. The authors reported that their technology could be applied to the detection of many different substances [50].

The sensing of gas generation by microbial fermentation in the gut has been taken to the point of clinical trials [51]. The gases, hydrogen, carbon dioxide, and oxygen, are the first examples of real-time in situ measurement of the chemical components of the gut. They represent the beginning of the process of unravelling the complex chemistry of the microbiome, potentially allowing researchers to follow its function in health and in disease [52,53].

Many of the semiochemicals released by the microbial contents of the gut are chemically identical to the messenger substances known to be present in the brain, leading to the conclusion that their significance could be due to the timing of their appearance relative to bodily events such as eating or sleeping, for example. The possession of an ingestible sensor calibrated to detect these semiochemicals would be an invaluable aid for understanding the progress of the noncommunicable conditions described by Burkitt as the Western disease [41]. In particular, the successful application of the scientific method requires the possession of reproducible, ideally quantitative, data. The simple measurement of faecal volume does not provide adequate data and has not been used since his studies. An ingestible sensor could be used as a quantitative surrogate marker for a deeper understanding of these conditions. Until the scientific method is established it is likely that the microbiome field will remain beset by unsubstantiated claims related to health benefits.

It should be possible to obtain much valuable data from animal experiments, as it is unlikely that microbial-animal interaction is specific to humans. As an example, we hypothesized that the use of antibiotics to enhance the growth of farm animals such as swine [54] is probably due to the degradation of their microbiome [12]. It is interesting to note that both poultry and fish farming also benefit from antibiotic growth promotion $[55,56]$ suggesting, if it is the same mechanism as growth promotion in mammals, that it stretches back at least to their very earliest forebears.

\section{Target Metabolites: A Surrogate Marker for Microbiome Effectiveness}

The target metabolite chosen depends on technical considerations including chemical selectivity, ease of measurement, and stability to the corrosive conditions of the gut [46]. Another key consideration must be the relevance of the target to the functions of the microbiome itself. Although many compounds are produced within the gut lumen, it is hard to know which behave as specific signaling molecules between the gut and human organs, namely semiochemicals. The short chain fatty acid salts, including acetate, propionate, and butyrate seem to be the end products of fibre metabolism working in an anoxic environment. As such, they represent a marker for an effective working microbiome, however, although they have profound effects on the immune system and the cells of the gut wall, in our opinion they are unlikely to be specific semiochemicals [57,58].

Serotonin has multiple functions throughout the body [59] and is produced within the gut lumen in the presence of the appropriate microbes [45]. However, there is also production and storage of serotonin within the adjacent enterochromaffin cells under the influence of short chain fatty acids, and therefore it could prove not to be a clear-cut target for an ingestible analytical system [60]. By contrast, dopamine production is known but is less well characterized within the gut lumen [43]. It is known to stimulate the immune system [44] and, although dopamine does not pass the blood-brain barrier, it may yet contribute to strengthening the microbiome-gut-brain axis [5]. An accidental observation 
made while studying obsessive-compulsive disorder led to the conclusion that dopamine generation in the brain affected insulin sensitivity in peripheral tissues [61]. At the moment there is no way of estimating the flux of dopamine formation in the gut, and therefore any contribution to diabetes and related conditions. An ingestible sensor calibrated to the determination of dopamine would allow researchers to study this potentially significant connection.

Interestingly, it has been shown that the mechanism of production of messenger chemicals (i.e., neurotransmitters) has been transferred from bacteria to animal cells via horizontal gene transfer. Such neurotransmitters include the catecholamine dopamine and the indole serotonin, along with histamine, acetylcholine, and even nitric oxide. The suggestion is that these transfers of genes took place separately, both before and after the divergence of animals from fungi [62].

\section{What is the Story So Far ... ?}

We have developed the concept of the microbiome as a single "mutualistic microbial community" with variable members, but which interacts with the host by one semiochemical allomone-kairomone mechanism of action [12]. It is believed that there is a limited number of critical metabolites that define an efficient microbiome and that measurement of these would provide an opportunity to quantify their effectiveness. This concept is under active consideration.

The causes of these modern noncommunicable diseases are bound to be complex and difficult to unravel. However, there are still some isolated people leading a mode of life widely removed from the Western lifestyle, similar to those originally studied by Denis Burkitt [41], that exhibit low levels of obesity and heart disease. Such people include the Tsimane, a mixed hunter-gatherer and farming community living in the Bolivian Amazon, under medical care since 2012. Although some of their medical data was reported in 2017, there was no mention of their microbiome status [63]. One problem is that there is no current way to measure the actual effectiveness of the microbiome as a whole, although microbial species may be tabulated.

In conclusion, identification of these critical metabolites and development of an in situ method of measurement could offer an unparalleled opportunity to study microbiome effectiveness, as well as the progression and eventual cure of microbiome-function deficiency diseases.

Conflicts of Interest: The authors declare no conflict of interest.

\section{References}

1. Reilly, J.J.; El-Hamdouchi, A.; Diouf, A.; Monyeki, A.; Somda, S.A. Determining the world-wide prevalence of obesity. Lancet 2018, 39, 1773-1774. [CrossRef]

2. Steel, Z.; Mamane, C.; Iranpour, C.; Chey, T.; Jackson, J.W.; Patel, V.; Silove, D. The global prevalence of common mental disorders: a systematic review and meta-analysis 1980-2013. Int. J. Epidemiol. 2014, 43, 476-493. [CrossRef] [PubMed]

3. Hill, D.A.; Spergel, J.M. The atopic march: critical evidence and clinical relevance. Ann. Allergy Asthma Immunol. 2018, 120, 131-137. [CrossRef] [PubMed]

4. Clemente, J.C.; Ursell, L.K.; Parfrey, L.W.; Knight, R. The impact of the gut microbiota on human health: an integrative view. Cell 2012, 148, 1258-1270. [CrossRef] [PubMed]

5. Torres-Fuentes, C.; Schellenkens, H.; Dinan, T.G.; Cryan, J.F. The microbiota-gut-brain-axis in obesity. Lancet Gastroenterol. Hepatol. 2017, 2, 747-756. [CrossRef]

6. Lowry, C.A.; Smith, D.G.; Sielber, P.H.; Schmidt, D.; Stamper, C.E.; Hassell, J.E.; Yamashita, P.S.; Fox, J.H.; Reber, S.O.; Brenner, L.A.; et al. The Microbiota, Immunoregulation, and Mental Health: Implications for Human Health. Curr. Environ. Health Rep. 2016, 3, 270-286. [CrossRef]

7. De Palma, G.; Collins, S.M.; Bercik, P. The microbiota-gut-brain axis in functional gastrointestinal disorders. Gut Microbes 2014, 5, 419-429. [CrossRef]

8. Opazo, M.C.; Ortega-Rocha, E.M.; Coronado-Arrazola, I.; Bonifaz, L.C.; Boudin, H.; Neunlist, M.; Bueno, S.M.; Kalgeris, A.M.; Riedel, C.A. Intestinal microbiota influences non-intestinal related autoimmune diseases. Front. Microbiol. 2018, 9, 432. [CrossRef] 
9. Vaarala, O.; Atkinson, M.A.; Neu, J. The "perfect storm" for type 1 diabetes - the complex interplay between intestinal microbiota, gut permeability, and mucosal immunity. Diabetes 2008, 57, 2555-2562. [CrossRef]

10. Greer, J.B.; O'Keefe, S.J. Microbial induction of immunity, inflammation, and cancer. Front. Physiol. 2011, 1, 168. [CrossRef]

11. Zhao, Q.; Elson, C.A. Adaptive immune education by gut microbiota antigens. Immunology 2018, 154, $28-37$. [CrossRef] [PubMed]

12. Jheeta, S.; Smith, D. Seeing the wood for the trees: A new way to view the human intestinal microbiome and its connection with non-communicable disease. Med. Hypoth. 2019, 125, 70-74. [CrossRef] [PubMed]

13. Lozupone, C.A.; Hamady, M.; Cantarel, B.L.; Coutinho, P.M.; Henrissat, B.; Gordon, J.I.; Knight, R. The convergence of carbohydrate active gene repertoires in human gut microbes. Proc. Natl. Acad. Sci. USA 2008, 105, 15076-15081. [CrossRef] [PubMed]

14. Hooks, K.B.; O'Malley, M.A. Dysbiosis and its discontents. mBio 2017, 8, e01492-17. [CrossRef] [PubMed]

15. Griffith, F. The significance of pneumococcal types. J. Hyg. 1928, XXVII, 113-159. [CrossRef] [PubMed]

16. Lederberg, J.; Tatum, E.L. Gene recombination in E. coli. Nature 1946, 158, 558. [CrossRef] [PubMed]

17. Stanier, R.Y.; Doudoroff, M.; Adelberg, E.A. General Microbiology; The MacMillan Press Ltd.: Basingstoke, UK, 1973; Chapter 14.

18. Kellenberger, E. The genetic control of the shape of a virus. Sci. Am. 1966, 215, 32-39. [CrossRef]

19. Koumandou, V.L.; Kossida, S. Evolution of the F0F1 ATP Synthase Complex in Light of the Patchy Distribution of Different Bioenergetic Pathways across Prokaryotes. PLOS Comput. Biol. 2014, 10, e1003821. [CrossRef]

20. Agioutantis, P.; Koumandou, V.L. Bioenergetic diversity of the human gut microbiome. Meta Gene 2018, 16, 10-14. [CrossRef]

21. Koumandou, V.L.; Kossida, S. Evolution of b-type cytochromes in prokaryotes. Peer J. PrePrints 2015, 3 , e1564v1.

22. Lozupone, C.A.; Stombaugh, J.I.; Gordon, J.I.; Jansson, J.K.; Knight, R. Diversity, stability and resilience of the human gut microbiota. Nature 2012, 489, 220-230. [CrossRef]

23. Sonnenburg, E.D.; Smits, S.A.; Tikhonov, M.; Higginbottom, S.A.; Wingreen, N.S.; Sonnenburg, J.L. Diet-induced Extinctions in the Gut Microbiota Compound over Generations. Nature 2016, 529, $212-215$. [CrossRef]

24. Hill, C.; Guarner, F.; Reid, G.; Gibson, G.R.; Merenstein, D.J.; Pot, B.; Morelli, L.; Canani, R.B.; Flint, H.J.; Salminen, S.; et al. Expert consensus document. The international scientific association for probiotics and prebiotics consensus statement on the scope and appropriate use of the term probiotic. Nat. Rev. Gastroenterol. Hepatol. 2014, 11, 506-514. [CrossRef] [PubMed]

25. AlFaleh, K.; Anabrees, J. Probiotics for the prevention of necrotising enterocolitis in preterm infants. Cochrane Database Syst. Rev. 2014, 4, CD005496. [CrossRef]

26. Underwood, M.A.; Salzman, N.H.; Bennett, S.H.; Barman, M.; Mills, D.A.; Marcobal, A.; Tancredi, D.J.; Bevins, C.L.; Sherman, M.P. A randomized placebo-controlled comparison of 2 prebiotic/probiotic combinations in preterm infants: impact on weight gain, intestinal microbiota, and fecal short-chain fatty acids. J. Paediatr. Gastroenterol. Nutr. 2009, 48, 216-225. [CrossRef] [PubMed]

27. Petrof, E.O.; Khoruts, A. From stool transplants to next-generation microbiota therapeutics. Gastroenterology 2014, 146, 1573-1582. [CrossRef]

28. Hamilton, M.J.; Weingarden, A.R.; Unno, T.; Koruts, A.; Sadowsky, M.J. High-throughput DNA sequence analysis reveals stable engraftment of gut microbiota following transplantation of previously frozen fecal bacteria. Gut Microbes 2013, 4, 125-135. [CrossRef]

29. Borody, T.J.; Campbell, J. Fecal microbiota transplantation: current status and future directions. Expert Rev. Gastroenterol. Hepatol. 2011, 5, 653-655. [CrossRef]

30. Poutahidis, T.; Kleinewietfeld, M.; Smillie, C.; Levkovich, T.; Perrota, A.; Bhela, S.; Varian, B.J.; Ibrahim, Y.M.; Lakritz, J.R.; Kearney, S.M.; et al. Microbial reprogramming inhibits Western diet-associated obesity. PLoS ONE 2013, 8, e68596. [CrossRef]

31. Lekunberri, I.; Subirats, J.; Borrego, C.M.; Balcazar, J.L. Exploring the contribution of bacteriophage to antibiotic resistance. Envir. Pollut. 2017, 220, 981-984. [CrossRef]

32. Jheeta, S. The Routes of Emergence of Life from LUCA during the RNA and Viral World: A Conspectus. Life 2015, 5, 1445-1453. [CrossRef] [PubMed]

33. Jheeta, S. The Landscape of the Emergence of Life. Life 2017, 7, 27. [CrossRef] [PubMed] 
34. Keen, E.C.; Bliskovsky, V.V.; Malagon, F.; Baker, J.D.; Prince, J.S.; Klaus, J.S.; Adhya, S.L.; Groisman, E.A. Novel "superspreader" bacteriophages promote horizontal gene transfer by transformation. mBio 2017, 8 , e02115-16. [CrossRef] [PubMed]

35. Pietilä, M.K.; Demina, T.A.; Atanasova, N.S.; Oksanen, H.M.; Bamford, D.H. Archaeal viruses and bacteriophages: comparisons and contrasts. Trends Microbiol. 2014, 22, 334-344. [CrossRef]

36. Laforest-Lapointe, I.; Arrieta, M.-C. Microbial eukaryotes: a missing link in gut microbiome studies. $m$ Systems 2018, 3, e00201-17. [CrossRef]

37. Margulis, L. Symbiogenesis and symbionticism. In Symbiosis as a Source of Evolutionary Innovation: Speciation and Morphogenesis; Margulis, L., Fester, R., Eds.; MIT Press: Cambridge, MA, USA, 1991; pp. 49-92.

38. Guerrero, R.; Margulis, L.; Berlanga, M. Symbiogenesis: the holobiont as a unit of evolution. Int. Microbiol. 2013, 16, 133-143.

39. Woese, C.R.; Fox, G.E. Phylogenetic structure of the prokaryotic domain: the primary kingdoms. Proc. Natl. Acad. Sci. USA 1974, 74, 5088-5090. [CrossRef]

40. Yarus, M. Life from an RNA World; Harvard University Press: Cambridge, MA, USA, 2010; Chapter 3.

41. Burkitt, D.P. Some diseases characteristic of modern western civilization. BMJ 1973, 1, 274-278. [CrossRef]

42. Semiochemicals of Forest and Shade Tree Insects in North America and Management Applications. Available online: https://iucat.iu.edu/iupui/5439806 (accessed on 11 September 2019).

43. Asano, Y.; Hiramoto, T.; Nishino, R.; Aiba, Y.; Kimura, T.; Yoshihara, K.; Koga, Y.; Sudo, N. Critical role of gut microbiota in the production of biologically active, free catecholamines in the gut lumen of mice. AJP Gastrointest. Liver Physiol. 2012, 303, G1288-G1295. [CrossRef]

44. Xue, R.; Zhang, H.; Pan, J.; Du, Z.; Zhou, W.; Zhang, Z.; Tian, Z.; Zhou, R.; Bai, L. Peripheral dopamine controlled by gut microbes inhibits invariant natural killer T cell-mediated hepatitis. Front. Immunol. 2018, 9 , 2398. [CrossRef]

45. Hata, T.; Asano, Y.; Yoshihara, K.; Kimura-Todani, T.; Miyata, N.; Zhang, X.-T.; Takakura, S.; Aiba, Y.; Koga, Y.; Sudo, N. Regulation of gut luminal serotonin by commensal microbiota in mice. PLoS ONE 2017, 12, e0180745. [CrossRef] [PubMed]

46. Kalantar-Zadeh, K.; Ha, N.; Ou, J.Z.; Berean, K.J. Ingestible sensors. ACS Sens. 2017, 2, 468-483. [CrossRef] [PubMed]

47. Yung, D.E.; Rondonotti, E.; Koulaouzidis, A. Review: capsule colonoscopy-a concise clinical overview of current status. Ann. Transl. Med. 2016, 4, 398. [CrossRef] [PubMed]

48. Peters-Strickland, T.; Pestreich, L.; Hatch, A.; Rohatagi, S.; Baker, R.A.; Docherty, J.P.; Markovtsova, L.; Raja, P.; Weiden, P.J.; Walling, D.P. Usability of a novel digital medicine system in adults with schizophrenia treated with sensor-embedded tablets of aripiprazole. Neuropsychiatr. Dis. Treat. 2016, 12, 2587-2594. [CrossRef]

49. Batra, S.; Baker, R.A.; Wang, T.; Forma, F.; DiBiasi, F.; Peters-Strickland, T. Digital health technology for use in patients with serious mental illness: a systematic review of the literature. Med. Devices (Auckl) 2017, 10, 237-251. [CrossRef]

50. Mimee, M.; Nadeau, P.; Hayward, A.; Carim, S.; Flanagan, S.; Jerger, L.; Collins, J.; McDonnell, S.; Swartwout, R.; Citorik, R.J.; et al. An ingestible bacterial-electronic system to monitor gastrointestinal health. Science 2018, 360, 915-918. [CrossRef]

51. Kalantar-Zadeh, K.; Berean, K.J.; Ha, N.; Chrimes, A.F.; Xu, K.; Grando, D.; Ou, J.Z.; Pillai, N.; Campbell, J.L.; Brkljača, R.; et al. A human pilot trial of ingestible electronic capsules capable of sensing different gases in the gut. Nat. Electron. 2018, 1, 79-87. [CrossRef]

52. Kalantar-Zadeh, K.; Yao, C.K.; Berean, K.J.; Ha, N.; Ou, J.Z.; Ward, S.A.; Pillai, N.; Hill, J.; Cottrell, J.J.; Dunshea, F.R.; et al. Intestinal gas capsules: a proof-of-concept demonstration. Gastroenterology 2016, 150, 37-39. [CrossRef]

53. Ou, J.Z.; Cottrell, J.J.; Ha, N.; Pillai, N.; Yao, C.K.; Berean, K.J.; Ward, S.A.; Grando, D.; Muir, J.; Harrison, C.J.; et al. Potential of in vivo real-time gastric gas profiling: a pilot evaluation of heat-stress and modulating dietary cinnamon effect in an animal model. Sci. Rep. 2016, 6, 33387. [CrossRef]

54. Cromwell, G.L. Why and how antibiotics are used in swine production. Anim. Biotechn. 2002, 13, 7-27. [CrossRef]

55. Davison, T.F.; Freeman, B.M. Physiological aspects of growth promotion in poultry. Vet. Res. Commun. 1983, 7, 59-68. [CrossRef] 
56. Reda, R.M.; Ibrahim, R.E.; Ahmed, E.-N.G.; El-Bouhy, Z.M. Effect of oxytetracycline and florfenicol as growth promoters on the health status of cultured Oreochromis niloticus. Egyptian J. Aquatic Res. 2013, 39, 241-248. [CrossRef]

57. Smith, P.M.; Howitt, M.R.; Panikov, N.; Michaud, M.; Gallini, C.A.; Bohlooly-Y, M.; Glickman, J.N.; Garrett, W.S. The microbial metabolites, short-chain fatty acids, regulate colonic Treg cell homeostasis. Science 2013, 341, 569-573. [CrossRef] [PubMed]

58. De Vadder, F.; Kovatcheva-Datchary, P.; Goncalves, D.; Vinera, J.; Zitoun, C.; Duchampt, A.; Bäckhed, F.; Mithieux, G. Microbiota-generated metabolites promote metabolic benefits via gut-brain neural circuits. Cell 2014, 156, 84-96. [CrossRef] [PubMed]

59. Berger, M.; Gray, J.A.; Roth, R.L. The expanded biology of serotonin. Annu. Rev. Med. 2009, 60, 355-366. [CrossRef] [PubMed]

60. Reigstad, C.S.; Salmonson, C.E.; Rainey III, J.F.; Szurszewski, J.H.; Linden, D.R.; Sonnenburg, J.L.; Farrugia, G.; Kashyap, P.C. Gut microbes promote colonic serotonin production through an effect of short-chain fatty acids on enterochromaffin cells. FASEB J. 2015, 29, 1395-1403. [CrossRef] [PubMed]

61. Ter Horst, K.W.; Lammers, N.M.; Trinko, R.; Opland, D.M.; Figee, M.; Ackermans, M.T.; Booij, J.; van den Munckhof, P.; Schuurman, P.R.; Fliers, E.; et al. Striatal dopamine regulates systemic glucose metabolism in humans and mice. Sci. Transl. Med. 2018, 10, eaar3752. [CrossRef]

62. Iyer, L.M.; Aravind, L.; Coon, S.L.; Klein, D.C.; Koonin, E.V. Evolution of cell-cell signaling in animals: did late horizontal gene transfer from bacteria have a role? Trends Genet. 2004, 20, 292-299. [CrossRef]

63. Kaplan, H.; Thompson, R.C.; Trumble, B.C.; Wann, L.S.; Allam, A.H.; Beheim, B.; Frohlich, B.; Sutherland, M.L.; Sutherland, J.D.; Stieglitz, J.; et al. Coronary atherosclerosis in indigenous South American Tsimane: A cross sectional cohort study. Lancet 2017, 389, 1730-1739. [CrossRef]

(C) 2020 by the authors. Licensee MDPI, Basel, Switzerland. This article is an open access article distributed under the terms and conditions of the Creative Commons Attribution (CC BY) license (http://creativecommons.org/licenses/by/4.0/). 